九州大学学術情報リポジトリ

Kyushu University Institutional Repository

\title{
Offspring Performance in the Pupal Parasitoid Pimpla (=Coccygomimus) luctuosa (Hymenoptera : Ichneumonidae) as Influenced by Host Age and Size
}

Ueno, Takatoshi

Laboratory of Insect Natural Enemies, Division of Biological Control, Department of Applied Genetics and Pest Management, Faculty of Agriculture, Kyushu University

https://doi.org/10.5109/4592

出版情報: 九州大学大学院農学研究院紀要. 49 (2)，pp. 321-329，2004-10-01. Faculty of Agriculture, Kyushu University バージョン：

権利関係 : 


\title{
Offspring Performance in the Pupal Parasitoid Pimpla (=Coccygomimus) luctuosa (Hymenoptera: Ichneumonidae) as Influenced by Host Age and Size
}

\author{
Takatoshi UENO* \\ Laboratory of Insect Natural Enemies, Division of Biological Control, \\ Department of Applied Genetics and Pest Management, Faculty of \\ Agriculture, Kyushu University, Fukuoka 812-8581, Japan \\ (Received June 25, 2004 Accepted July 13, 2004)
}

\begin{abstract}
The age and size of hosts are known to have a profound effect on host suitability for many species of parasitoid wasps. Relationships between host suitability and host type are essential information in determining an appropriate range of hosts that is used for mass rearing of parasitoids but this information is lacking for Pimpla (=Coccygomimus) luctuosa Smith, a pupal solitary parasitoid wasp of many lepidopteran pests. Accordingly, the effects of host age and size on the offspring survival and fitness of $P$. luctuosa were examined in the present study. Old host pupae produced fewer wasp offspring than young host pupae did. The size of hosts also affected the offspring survival, and the mortality of offspring was higher in smaller hosts. No significant interaction was detected between host age and size effects on the offspring survival. Smaller wasp offspring were produced when hosts were smaller. Likewise, smaller wasp offspring emerged from older host pupae. Thus, the results demonstrated that old hosts were of poor quality for the developing wasp offspring of $P$. luctuosa. The relationships between host type and offspring performance in $P$. luctuosa were discussed.
\end{abstract}

\section{INTRODUCTION}

Investigation of the relationship between host type (i.e. host stage, age, size, color, strains, etc.) and suitability has been an essential approach in the study of biological control with parasitoids (Vinson and Iwantsch, 1980; Jervis and Kidd, 1996). Knowing what types of host are suitable for offspring development is necessary to determine an appropriate range of hosts used for mass rearing of parasitoids. The knowledge also provides information on the potential range of the hosts in the field.

Host size is one of the most important factors affecting the suitability of hosts for many parasitoid species (Vinson and Iwantsch, 1980; King, 1987, 1993; Godfray, 1994). A correlation between host size and offspring parasitoid size is demonstrated for many species of solitary parasitoids (e.g. Charnov et al., 1981; King, 1993; West et al.; 1996). This correlation arises because the amount of resources that is available to developing parasitoids is largely determined by the size of hosts.

The size of parasitoids is a major determinant for their fitness; smaller individuals in general are less fecund and have shorter life span (e.g. King, 1993; Visser, 1994; West et al., 1996; Ueno, 1999). Smaller parasitoids may thus be less successful in biological control. In other word, the size of parasitoids can be an index of their quality for biological control.

\footnotetext{
* Corresponding author (E-mail: ueno@grt.kyushu-u.ac.jp)
} 
Host pupal age is another factor influencing host suitability for pupal parasitoids (e.g. Fuester et al., 1989; King, 1990; Ueno, 1997; Husni et al., 2001). During the pupal stage, larval tissue is reconstructed dramatically to adult tissue with increasing pupal age. This physiological change can affect host suitability. The amount of resources that is available to developing parasitoids should be reduced with host age if adult host tissue would not be edible for the parasitoids. As a result, the size of emerging parasitoids can be smaller when old host pupae have been parasitized. If this could be the case, it would be desirable to use young hosts for parasitoid mass-rearing.

Pimpla (=Coccygomimus) luctuosa Smith is a large solitary pupal endoparasitoid, distributed widely in Japan and other parts of East Asia (Townes et al., 1965; Yasumatsu and Watanabe, 1965). It is commonly found in a variety of agricultural fields, and is recorded as a parasitoid of many lepidopteran pests (Townes et al., 1965; Yasumatsu and Watanabe, 1965; Ueno and Tanaka, 1994). Therefore, P. luctuosa may have a significant impact on pest insect populations.

The biological characteristics and life history of $P$. luctuosa are not fully understood, however. No study has examined the relationships between host age and suitability in this parasitoid. Here, I examined the offspring performance of the parasitoid P. luctuosa in hosts of different ages and sizes. For this purpose, offspring survival and size were measured when $P$. luctuosa developed on hosts of different ages and sizes. Based on the results, host suitability/host type relationships in this parasitoid were discussed.

\section{MATERIALS AND METHODS}

\section{Parasitoid and host}

All experiments were conducted with larboratory populations of Pimpla luctuosa and a laboratory host, Galleria mellonella. The colony of P. luctuosa was originated from adult wasps collected in Kobe, Hyogo Prefecture. Methods for maintenance of the colony were described by Ueno and Tanaka (1994). Newly emerged female parasitoids were placed individually in plastic containers $(10 \mathrm{~cm}$ in diameter, $4.5 \mathrm{~cm}$ in height), together with tissue paper saturated with diluted honey. The tissue paper was replaced twice a week thereafter. The containers were kept at $20 \pm 1^{\circ} \mathrm{C}$. Host cocoons containing fresh pupae were presented to female $P$. luctuosa in the plastic containers. Parasitized hosts were held at $20 \pm 0.5^{\circ} \mathrm{C}$ until wasp emergence. Newly emerged wasps were paired and placed in the plastic containers and maintained as mentioned above.

\section{Host age effects}

Newly emerged wasps were paired and placed in the plastic containers. After mating, males were removed from the containers. As a pre-experimental treatment, females were presented with two host fresh cocoons for three days on a daily basis. Twelve female wasps (F2 or F3 generations) were used in the experiments.

Hosts of variable sizes were divided into two age classes: 1-3 days old and 5-7 days old hosts. A random mixture of these two classes, was presented to individual test females. Experiments were conducted with females between day 5 and day 16 after wasp emergence. Host cocoons were individually offered to female wasps, and their response to the hosts was directly observed under a binocular stereoscope. During oviposion, it is 
possible to see an egg passing through the base of the ovipositor (Ueno, 1995), and oviposition on the hosts can readily be confirmed. Care was taken to avoid superparasitism and host feeding. This procedure was repeated 3-4 times per female every other day; thus, 3-4 hosts were presented to each female during the experimental day. This was because female $P$. luctuosa carried a relatively small number of mature eggs (Ueno and Tanaka, 1994).

Hosts were removed immediately after oviposition and were weighed. In the present study, host weight was used as an index of the size of hosts. All parasitized hosts were kept at $25 \pm 0.5^{\circ} \mathrm{C}, 60-70 \% \mathrm{RH}$, and a photoperiod of $16: 8$ (L:D) h. Parasitized hosts were checked daily to confirm offspring emergence. When wasp offspring emerged, the forewing length and head width' of the offspring were measured. In the present study, I evaluated offspring performance in young and old hosts based on the survival and size.

\section{Statistical analyses}

Statistical treatments were made with the aid of JMP (SAS Institute, 2001). Because no maternal effects were detected, all data were pooled for the following analyses. Multiple logistic regression analyses and ANCOVA were performed to examine the effects of host size and age on wasp production and size. Linear regression analyses were applied to examine the relationships between host size and wasp size.

\section{RESULTS AND DISCUSSION}

In total, 111 hosts were parasitized by female $P$. luctuosa during the experiment. A multiple logistic regression analysis was performed to assess the effects of host weight, age and the interaction between the two factors on the offspring production in $P$. luctuosa. The whole model obtained was significant $\left(x^{2}=11.49, \mathrm{df}=3, P=0.009\right)$. The analysis showed that both host weight and age had significant effects on the offspring production (Table 1).

Table 1. The result of a multiple logistic regression analysis for assessing factors affecting the offspring production of Pimpla luctuosa

\begin{tabular}{lccc}
\hline Factors & df & Wald $x^{2}$ & $P$ values \\
\hline Host age & 1 & 6.29 & 0.012 \\
Host weight & 1 & 5.37 & 0.021 \\
Interaction & 1 & 1.18 & 0.28 \\
\hline
\end{tabular}

The percentages of hosts yielding wasp offspring differed between host age classes (Chi-squared test; $x^{2}=5.52$, df $=1, P=0.018$ ); and old hosts produced fewer wasp offspring (Fig. 1). The percentage of hosts producing wasp offspring was $89.2 \%$ when young pupae of $G$. mellonella had been parasitized; most of offspring P. luctuosa developed successfully to adulthood, demonstrating that $G$. mellonella is a highly suitable host for P. luctuosa.

Old $G$. mellonella pupae were less suitable than young ones but still appeared to be 


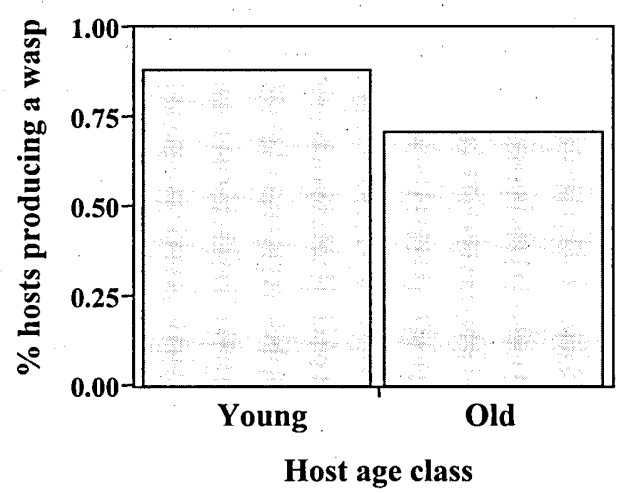

Fig. 1. The effect of host pupal age on offspring production of $P$. luctuosa. The production differed between the groups (Chi-squared test; $P<0.05$ ).

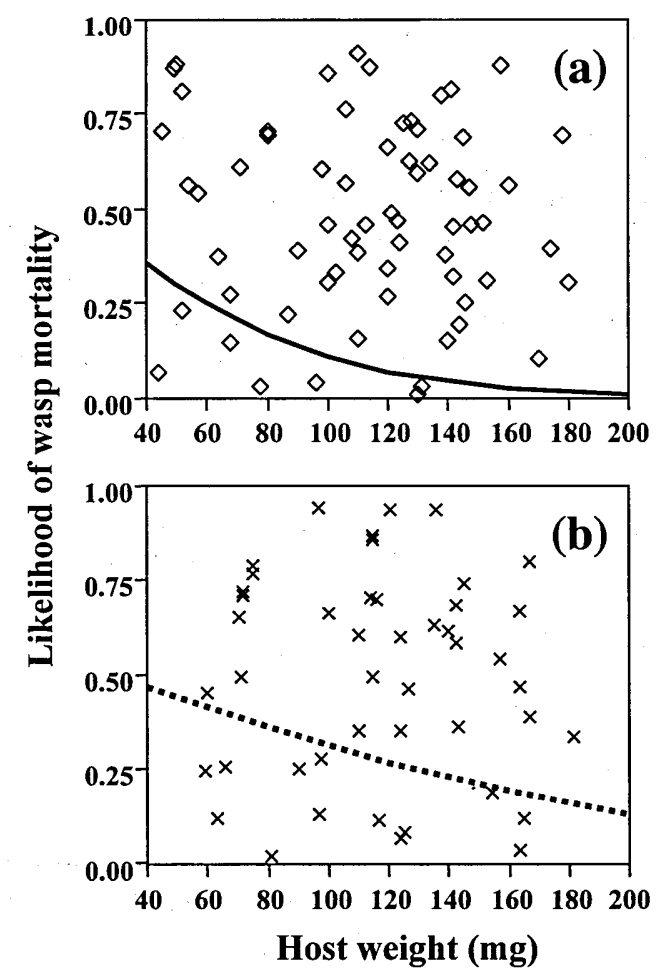

Fig. 2. The relationships between host size and offspring mortality of $P$. luctuosa. The regressions were significant for young hosts (above, logistic regression analyses; $P<0.05$ ) but not for old hosts (below, $P>0.05$ ). 
enough for mass-rearing $P$. luctuosa. Offspring survival of $P$. luctuosa in old host pupae was $71.7 \%$, the value of which was lower than that in young host pupae but the value was reasonably high. Thus, the age of $G$. mellonella pupae by itself may not be a matter upon mass rearing in that wasp production is high regardless of host age.

The likelihood of wasp production significantly increased with increasing host weight when host pupae were young (Fig. 2a; simple logistic regression analysis, $x^{2}=4.73, \mathrm{df}=1$, $P=0.029$ ) but did not so when hosts were old (Fig. $2 \mathrm{~b}, x^{2}=1.24$, df $=1, P=0.26$ ). Therefore, host size affects offspring survival of $P$. luctuosa but the size effect may not be strong.

A negative relationship between host size and offspring mortality is reported for a number of parasitoid wasps (Vinson and Iwantsch, 1980; King, 1987). Such a relationship could be the result of shortage of food. An alternative explanation is that smaller hosts are more likely to die shortly after parasitism due to parasitoid load, which results in indirect mortality of parasitoids developing within the hosts.

ANCOVAs were performed to assess the effects of host weight and age on the offspring size, i.e. forewing length. The whole models were highly significant $\left(r^{2}=0.67, F=\right.$ 42.94, $\mathrm{df}=3, P<0.0001$ for male offspring; $r^{2}=0.70, F=21.39, \mathrm{df}=3, P<0.0001$ for female offspring), and both host weight and age significantly affected the offspring size in both sexes (Table 2).

Table 2. The result of ANCOVAs for assessing factors affecting the offspring size of Pimpla luctuosa

\begin{tabular}{llcc}
\hline Factors & df & $F$ & $P$ values \\
\hline Male offspring & & & \\
Host age & 1 & 9.31 & 0.003 \\
Host weight & 1 & 124.04 & $<0.0001$ \\
Interaction & 1 & 1.55 & 0.22 \\
Female offspring & & & 0.022 \\
Host age & 1 & 42.25 & $<0.0001$ \\
Host weight & 1 & 1.68 & 0.21 \\
Interaction & 1 & & \\
\hline
\end{tabular}

Smaller wasps were produced from smaller young hosts regardless of the sex of wasps emerging. Forewing length of wasp offspring was smaller when they were produced from smaller young hosts (Fig. 3 and $4 ; r^{2}=0.82, F=169.9, \mathrm{df}=1, P<0.0001$ for male offspring; $r^{2}=0.78, F=57.2, \mathrm{df}=1, P<0.0001$ for female offspring). Likewise, head width of parasitoid offspring emerging from smaller hosts was narrower on young host pupae (Fig. 5 and $6 ; r^{2}=0.36, F=14.7, \mathrm{df}=1, P=0.0007$ for male offspring; $r^{2}=0.70, F=$ 23.5, $\mathrm{df}=1, P=0.0007$ for female offspring).

For old host pupae, there was also a significant relationship between host weight and forewing length for males (Fig. $3 ; r^{2}=0.67, F=42.94$, $\mathrm{df}=1, P<0.0001$ ) but this was not the case for females $\left(r^{2}=0.39, F=0.63, \mathrm{df}=1, P=0.57\right)$. Similarly, head width of male parasitoids was wider in larger, old hosts (Fig. $5 ; r^{2}=0.21, F=5.30, \mathrm{df}=1, P=0.032$ ) but again this was not the case for female parasitoids $\left(r^{2}=0.71, F=15.9, \mathrm{df}=1, P=0.16\right)$.

The lack of significant relationships between host size and parasitoid size for females 


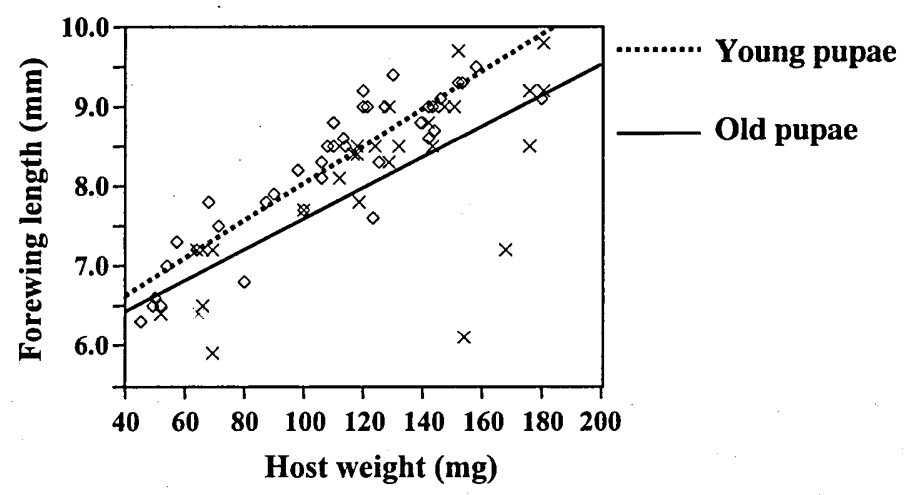

Fig. 3. The relationships between host size and forewing length of male offspring $P$. luctuosa. The regressions were significant for both host age classes (simple regression analyses; $P<0.001$ ).

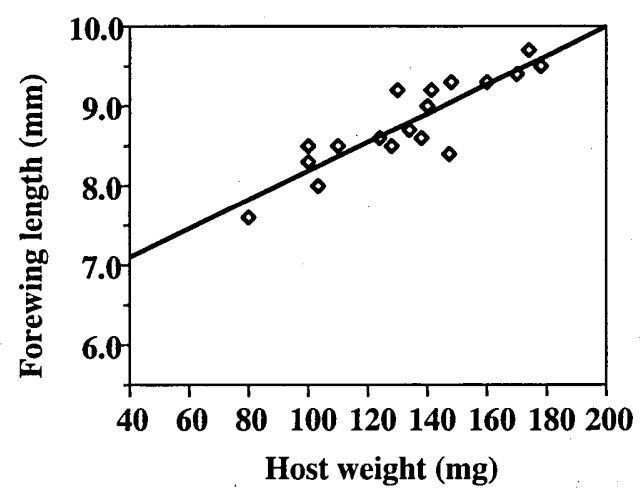

Fig. 4. The relationships between host size and forewing length of female offspring $P$. luctuosa on young hosts. The regression was significant (simple regression analyses; $P<0.001$ ).

is due to a small sample size $(N=3)$. Female offspring is rarely produced from old host pupae probably because $P$. luctuosa can control the offspring sex ratio in response to hosts of different quality and because it lays male eggs in small or old hosts (Ueno, 1998).

The size of parasitoids emerging from the host is commonly affected by the amount of resources available (King, 1987, 1993; Godfray, 1994). For many solitary species, host size, which reflects the amount of host resources, is a major factor that positively relates to the size of parasitoids produced from the host. This was also the case for P. luctuosa. The presence of positive correlations between host size and wasp size indicates provision of large classes of hosts is preferable in mass rearing of $P$. luctuosa. In many parasitoids, 


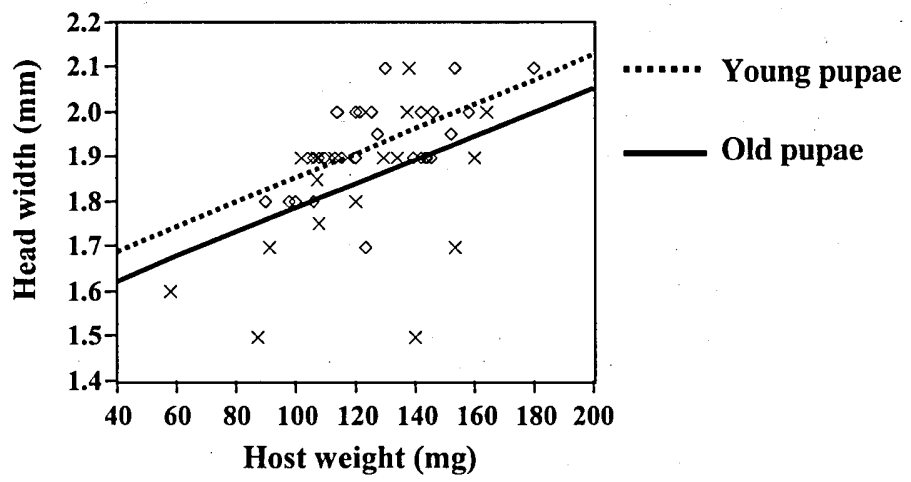

Fig. 5. The relationships between host size and head width of male offspring $P$. luctuosa. The regressions were significant for both host age classes (simple regression analyses; $P<0.001$ ).

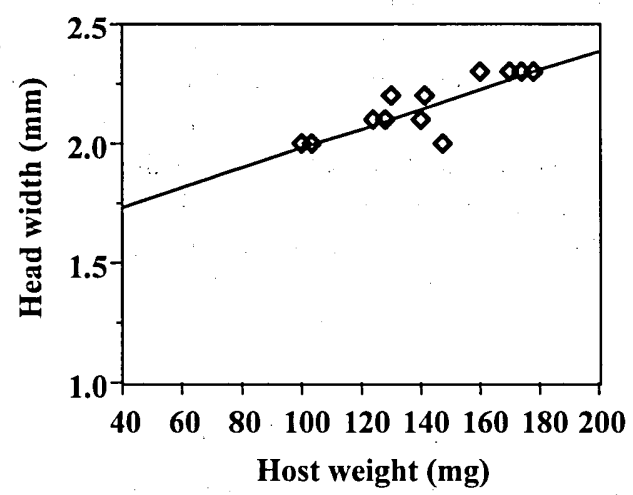

Fig. 6. The relationship between host size and head width of female offspring $P$. luctuosa on young hosts. The regression was significant (simple regression analyses; $P<0.001$ ).

it is known that the reproductive success is higher for larger wasps; larger individuals are more fecund and have a longer life span (King, 1993; Visser, 1994; West et al., 1996; Ueno, 1999). Larger individuals can therefore be of high quality as a biocontrol agent.

The present study showed that the offspring survival of $P$. luctuosa differed between young and old host pupae (Fig. 1). Although $P$. luctuosa was able to develop successfully on both young and old hosts, offspring mortality was higher in old class of host pupae. The results indicate that host suitability is lower in older host pupae. For a number of pupal parasitoid wasps of Lepidoptera, the age at which the host pupa is parasitized influences offspring survival and performance (e.g. Sandlan, 1982; Hailemichael et al., 
1994; Ueno, 1997; Husni et al., 2001). Thus, a decrease of host suitability with host pupal age appears to be the general rule for pupal parasitoids of Lepidoptera.

A number of host factors can determine the survival of developing parasitoids (Vinson and Iwantsch, 1980, Quicke, 1997; Thompson, 1999). A decrease of host suitability with host pupal age can be resulted from the nutritional inadequacy in old host pupae. During the pupal stage, larval tissue is reconstructed dramatically to adult tissue with increasing pupal ages. Adult tissue newly constructed is sclerotized, and the developing larva of $P$. luctuosa is likely to have difficulty to digest such sclerotized tissues. If this could be the case, the size of emerging wasp offspring would be smaller on older host pupae because the amount of host resources edible for the developing offspring should be fewer.

In fact, the size of wasp offspring was smaller on old host pupae than young host pupae (Figs. 3 and 4). This result supports the idea that the amount of host resources available for wasp offspring is fewer in older hosts. Thus, older hosts are of poorer quality for $P$. luctuosa in that the offspring size becomes smaller. Further, the offspring sex ratio of $P$. luctuosa is highly male-biased on old hosts (Ueno, unpublished). Provision of young class of host pupae would thus be desirable upon the mass rearing.

There was a negative relationship between host size and parasitoid mortality; smaller hosts produced fewer parasitoid offspring (Fig. 2). In addition, smaller hosts produced smaller parasitoids (Figs. 3 and 4). Emergence of such relationships would be a logical consequence because smaller hosts should contain fewer food resources available to the developing parasitoid. Smaller hosts are thus of poorer quality for $P$. luctuosa.

A positive correlation between host size and the resulting parasitoid size is commonly found for the majority of solitary parasitoids examined so far (King, 1987, 1993), including P. luctuosa (Ueno, 1998). Provision of large classes of hosts is desirable to efficiently rear $P$. luctuosa with high fitness. In conclusion, host pupae of young and large class should be selected to use for mass rearing of $P$. luctuosa.

\section{ACKNOWLEDGEMENTS}

This work was partly supported by grants from the Ministry of Education, Sciences, Sports and Culture of Japan (No. 13760039 and 15208007).

\section{REFERENCES}

Charnov, E. L., R. L. Los-den Hartogh, W. T. Jones and J. van den Assem 1981 Sex ratio evolution in a variable environment. Nature, 289: 27-33

Fuester, R. W., P. B. Taylor and A. Eisenberg 1989 Suitability of prepupae and pupae of the Gypsy moth (Lepidoptera: Lymantriidae) as hosts of Coccygomimus disparis (Hymenotpera: Ichneumonidae). Environ. Entomol., 18: 338-341

Godfray, H. C. J. 1994 Parasitoids: Behavioral and evolutionary ecology. Princeton University Press, Princeton

Hailemichael, Y., J. W. Smith Jr. and R. N. Wiedenmann 1994 Host-finding behavior, host acceptance, and host suitability of the parasite Xanthopimpla stemmator. Entomol. Exp. Appl., 71: 155-166

Husni, Y. Kainoh and H. Honda 2001 Effects of host pupal age on host preference and host suitability in Brachymeria lasus (Hymenoptera: Chalciddiae). Appl. Entomol. Zool., 36: 97-102

Jervis, M. A. and N. A. C. Kidd 1996 Insect Natural Enemies. Chapman \& Hall, London

JMP 2001 JMP version 4.0. SAS Institute Inc., Cary, NC

King, B. H. 1987 Offspring sex ratios in parasitoid wasps. Q. Rev. Biol., 62: 367-396 
King, B. H. 1990 Sex ratio manipulation by the parasitoid wasp Spalangia cameroni in response to host age: a test of the host-size model. Evol. Ecol., 4: 149-156

King, B. H. 1993 Sex ratio manipulation by parasitoid wasps. In "Evolution and Diversity of Sex Ratio in Insects and Mites", ed. By Wrensch, D. L., Ebbert, M., Chapman \& Hall, New York, pp 418-441

Quicke, D. L. J. 1997 Parasitic Wasps. Chapman \& Hall, London

Sandlan, K. 1982 Host suitability and its effects on biology of Coccygomimus turionellae (Hymenoptera: Ichneumonidae). Ann. Entomol. Soc. Am., 75: 217-221

Thompson, S. N. 1999 Nutrition and culture of entomophagous insects. Annu. Rev. Entomol., 44: 561-592

Townes, H., S. Momoi and M. Townes 1965 A catalogue and reclassification of the Eastern Palearctic Ichneumonidae. Memoris of The American Entomological Institute No. 5.

Ueno, T. 1995 Abdominal tip movements during oviposition by two parasitoids (Hymenoptera Ichneumonidae) as an index of predicting the sex of depositing eggs. Appl. Entomol. Zool., 30: $588-590$

Ueno, T. 1997 Host age preference and sex allocation in the pupal parasitoid Itoplectis naranyae (Hyemoptera: Ichneumonidae). Ann. Entomol. Soc. Am., 90: 640-645

Ueno, T. 1998 Sex allocation by a parasitoid wasp (Hymenoptera: Ichneumonidae) to different host species: a question for the mechanism of host size estimation. J. Insect Behav., 11: 811-821

Ueno, T. 1999 Host-size-dependent sex ratio in a parasitoid wasp. Res. Popul. Ecol., 41: 47-57

Ueno, T. and T. Tanaka 1994 Comparative biology of six polyphagous solitary pupal endoparasitoids (Hymenoptera: Ichneumonidae): differential host suitability and sex allocation. Ann. Entomol. Soc. Am., 87: 592-598

Vinson, S. B. and G. F. Iwantsch 1980 Host suitability for insect parasitoids. Ann. Rev. Entomol., 25: 397-419

Visser, M. E. 1994 The importance of being large: the relationship between size and fitness in females of the parasitoid Aphaereta minuta (Hymenoptera: Braconidae). J. Anim. Ecol. 63: 963-987

West, S. A., K. E. Flanagan and H. C. J. Godfray 1996 The relationship between parasitoid size and fitness in the field, a study of Achrysocharoides zwoelferi (Hymenoptera: Eulophidae). J. Anim. Ecol. 65: 631-639

Yasumatsu, K. and C. Watanabe 1965 A tentative catalogue of insect natural enemies of injurious insects in Japan. Part 2. Host parasite-predator catalogue. Entomol. Lab., Fac. Agric., Kyushu Univ. Press, Fukuoka 